\title{
Empirical Arias Intensity attenuation relationships for the seismic hazard analysis of Greece
}

\author{
G.-A. Tselentis, L. Danciu \& F. Gkika \\ Seismological Laboratory, University of Patras, Greece
}

\begin{abstract}
New empirical attenuation relationships of Arias Intensity for various site conditions based on the strong-motion data recorded in Greece are presented. With regard to attenuation relationships for the region of Greece, there are no Arias Intensity empirical attenuation models available today that may be used in seismic hazard analysis. For each site class, the attenuation relationship of Arias Intensity is expressed as a function of moment magnitude and epicentral distance and it is derived using a mixed effects regression analysis method. As a final result, probabilistic seismic hazard maps in terms of Arias Intensity have been developed for the territory of Greece.

Keywords: Arias Intensity, attenuation relationships, seismic hazard, Greece.
\end{abstract}

\section{Introduction}

Attenuation relationships are the core of seismic hazard analyses. They are developed by statistical analyses performed on a large number of records which were obtained in compatible seismotectonic regions. Traditionally the empirical attenuation relationships are developed in terms of peak acceleration or spectral acceleration and they are largely (but not entirely) data dependent. Ground motion parameters other than the commonly used spectral and peak acceleration can significantly affect the nonlinear response and performance of structures. These parameters incorporate in their definition amplitude, frequency content, and duration of the ground motion and are more adequate to describe the destructiveness potential of an earthquake. One such parameter is the Arias Intensity [1]. Over the last decades several Arias Intensity empirical attenuation relations have been presented [2-5]. These attenuation relations are in most cases 
similar in form, with magnitude and distance from source to site as the independent variable. The parameters are estimated by statistical fitting the relationships to the data by means of regression analysis. In a manner similar to the above mentioned methodologies, a new empirical attenuation relationship for Arias Intensity is presented. Finally these new empirical attenuation relationships were used for seismic hazard analyses in the territory of Greece.

\section{Data and methodology}

The strong motion records used in this article were selected from Greek accelerograms provided by the European Strong Motion Database [6]. A preliminary analysis of the data set was performed. The magnitude scale, which will be referred to as $M$ in this article corresponds to the moment magnitude. The regression analysis was performed in terms of epicentral distance $(R)$. The data distribution with respect to magnitude and epicentral distance is illustrated in fig. 1. Epicentral distance is a reliable parameter to characterize the source to site distance because surface geology in Greece does not show evident seismogenic faults [4] in most cases.

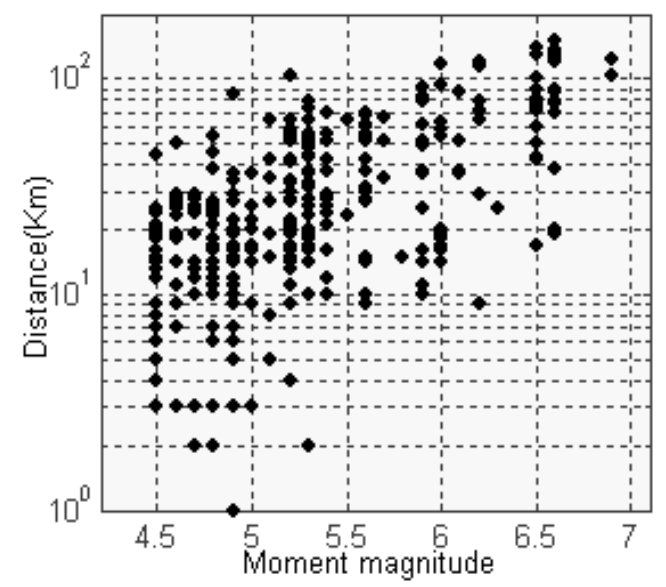

Figure 1: Distribution of strong motion recordings with respect to magnitude and epicentral distance.

The geological site conditions were classified into three representative profiles: rock (soil category A: $V_{s}>800 \mathrm{~m} / \mathrm{s}$ ); stiff-soil (soil category B: $V_{s}=360-665 \mathrm{~m} / \mathrm{s}$ ); soft soil (soil category C: $V_{s}=200-360 \mathrm{~m} / \mathrm{s}$ ).

The records with no reliable information on magnitude, epicentral distance, focal depth, soil properties or fault mechanism were excluded. In the present analysis, a style-of-faulting parameter is not explicitly modeled.

Arias Intensity $\left(I_{a}\right)$ as defined by Arias [1] is the total energy per unit weight stored by a set of undamped simple oscillators at the end of an earthquake. The Arias Intensity for ground motion in the east-west direction is calculated from 


$$
I_{a X}=\frac{2 \pi}{g} \int_{0}^{t_{0}}\left[a_{X}(t)\right]^{2} d t
$$

where $I_{a X}$ is the Arias Intensity in the east-west direction, $a_{X}(t)$ the acceleration time history in the east-west direction and $t_{0}$ is the total duration of ground motion. $I_{a X}$ is a measure of energy, which is scalar in nature, $I_{a}$ is the sum of two horizontal components calculated as follows: $I_{a}=I_{a X}+I_{a Y}$. Using the recorded strong motion data for these earthquakes, the $I_{a}$ values were computed.

A nonlinear mixed effects model [7] was used to determine the regression coefficients in the empirical model for Arias Intensity. This model can be viewed as a two-stage model, with the error divided into inter-event and intra-event terms. The intra-event residual $(\varepsilon)$ represents the difference between any single data point and the median prediction for that event, while the inter-event residual $(\eta)$ represents the deviation of the median prediction for a single event from the median prediction based on the entire data set. The intra-event and inter-event error terms are assumed normally distributed with mean of zero and standard errors of $\sigma$ and $\tau$, respectively. The total standard error for this mixed effects model is $\sqrt{\sigma^{2}+\eta^{2}}$. The parameters in the model are estimated by maximum likelihood. The predictive modeling adopted for the attenuation is represented by the following equation:

$$
\log _{10}\left(Y_{i j}\right)=a+b M_{i}+c \log _{10} \sqrt{{R_{i j}{ }^{2}+h_{i j}{ }^{2}}^{2}}+\varepsilon_{i j}
$$

where $Y_{i j}$ is the sum of the two horizontal components of the Arias Intensity in $\mathrm{m} / \mathrm{s}^{2}$ from the $j$ th record of the $i$ th event; $M_{i}$ is the moment magnitude of the $i$ th event, $R_{i j}$ is epicentral distance from the $i$ th event to the location, and $h_{i j}$ is focal depth from the $i$ th event to the location. The error term in eqn (2) is normally distributed with zero mean and standard deviation $\sigma^{2}$.

The NLME toolbox [7] available with the S-plus software [12] has been used to fit the data and to estimate the parameters $a, b, c$. Following the described methodology, the empirical attenuation relationships for Arias intensity were defined in terms of soil classification. These relations are presented as the next equations:

$$
\begin{aligned}
& \text { Rock: } \log _{10}\left(I_{a}\right)=0.74 M-1.56 \log _{10}\left(\sqrt{R^{2}+h^{2}}\right)-3.49+\varepsilon_{\text {rock }} \\
& \text { Stiff soil: } \log _{10}\left(I_{a}\right)=M-1.57 \log _{10}\left(\sqrt{R^{2}+h^{2}}\right)-4.80+\varepsilon_{\text {stiff }} \\
& \text { Soft soil: } \log _{10}\left(I_{a}\right)=1.18 M-1.81 \log _{10}\left(\sqrt{R^{2}+h^{2}}\right)-5.23+\varepsilon_{\text {soft }}
\end{aligned}
$$


The standard error terms $\varepsilon_{\text {rock }}=0.679, \varepsilon_{\text {stiff }}=0.520, \varepsilon_{\text {soft }}=0.305$ show that the aleatory variability in the predictability of Arias Intensity is large. This is not a disadvantage because it have been accepted that Arias Intensity has the largest aleatory variability in its prediction compared to the other intensity measures [5]. In eqns (3), (4) and (5), $h$ represents the effective depth of shallow events and the corresponding value for Greece is $h=7 \mathrm{~km}$ [9]. The empirical attenuation relationships for Arias Intensity for the three soil classifications are plotted in fig. 2 .

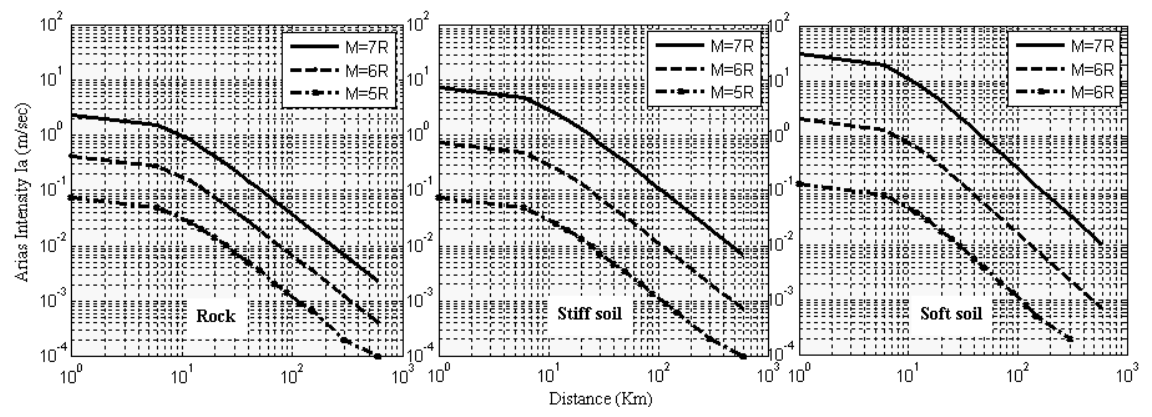

Figure 2: Proposed empirical attenuation relationships for Arias Intensity.

The regressed values of Arias Intensity for soft and stiff soil are higher than those for rock sites because of local soil amplification. Increase in Arias Intensity can be partially attributed to the longer duration of earthquake motion associated with soft soil sites relative to nearby rock sites [3].

For the region of interest in this study - Greece - there are no definitive Arias Intensity empirical attenuation models available today that may be used in comparison. Focusing in the area of Greece and Italy, Paciello et al. [4] presented attenuation laws for Arias Intensity and other ground motion parameters. These authors used the same definition for distance, magnitude, soil classification thus their relationship is suitable for comparison.

Another comparable relationship is that proposed by Travasarou et al. [5]. Fig. 3 , presents the derived relationships for three different earthquake magnitudes and compares them with the results of Paciello et al [4] and Travasarou et al. [5]. The relation for rock sites in this study is similar to that of Travasarou et al. [5] although the use of effective depth in this study increases the variance of the dataset. For intermediate magnitude events $(M=6)$, similar values for all the relationships are set. Comparing the values for large magnitude $(M=7)$ events and smaller epicenter distances, Arias Intensity appears to be overestimated by Paciello et al. [4]. Differences appear also for small magnitude events $(M \leq 6)$ were the values predicted by Paciello et al. [4] are underestimated. Some additional discrepancies can be explained by differences in the distance, soil category, fault-type definition and regression analysis method. It should be noted that the presented relationship does not make a distinction among different fault mechanisms. 


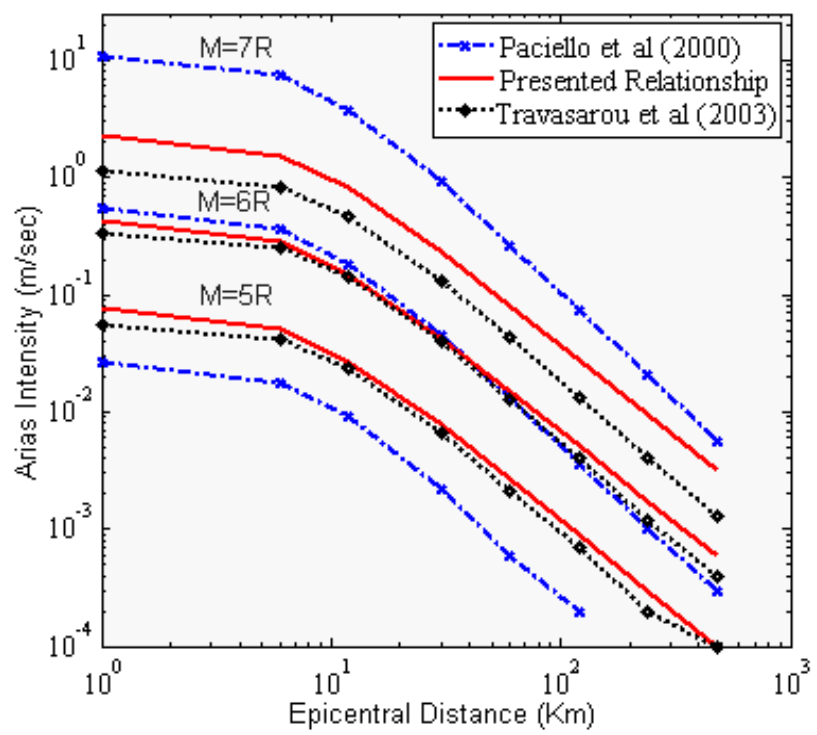

Figure 3: Comparison of proposed attenuation relationship with two existing relationships for three magnitude earthquakes at a rock sites.

\section{Probabilistic Arias Intensity maps}

The Aegean region constitutes the overriding plate of the Africa-Eurasia convergent plate system, in the eastern Mediterranean. Tectonic activity that takes place in the territory of Greece has been clearly expressed by the historical and recent seismicity and the strain rates estimated by GPS measurements [10]. Fig. 4 depicts the historic and recent seismicity of Greece [11] and the seismogenic source zones proposed by Papaioannou and Papazachos [12].

The model for the occurrence of ground motions at a specific site in excess of a specified level is assumed to be that of a Poisson process. This follows if the occurrence of earthquakes is a Poisson process and if the probability that any one event will produce site ground motions in excess of a specified level is independent of the occurrence of other events. The probability that a ground motion level $z$ is exceeded at a site in unit time is thus expressed as:

$$
\mathrm{P}(Z>z)=1-\mathrm{e}^{-v(z)}
$$

where $v(z)$ is the mean number of events per unit time in which $Z$ exceeds $z$. With $N$ seismic sources and seismicity model parameters $S_{n}$ for each source $n$, the mean number of events per unit time in which ground motion level $z$ is exceeded can be written as:

$$
v(z)=\sum_{n=1}^{N} v_{n}\left(z \mid S_{n}\right)
$$


where

$$
v_{n}\left(z \mid S_{n}\right)=\sum_{i, j} \lambda_{n}\left(M_{i} \mid S_{n}\right) P_{n}\left(r_{j} \mid M_{i} S_{n}\right) G_{n}\left(z \mid r_{j} M_{i} S_{n}\right)
$$

$\lambda_{n}\left(M_{i} \mid S_{n}\right)$ is the mean number of events per unit time of magnitude $M_{i}$ $\left(M_{i} \in\left[M_{\min }, M_{\max }\right]\right)$ in the source $n$ with seismicity parameters $S_{n} ; P_{n}\left(r_{j} \mid M_{i} S_{n}\right)$ is the probability that a significant site -source distance is $r_{j},\left(r_{j} \in\left[r_{\min }, r_{\max }\right]\right)$ given an event of magnitude $M_{i}$ in source $n$ with seismicity parameters $S_{n} ; G_{n}\left(\mathrm{z} \mid r_{j} M_{i} S_{n}\right)$ is the probability that the ground motion level $z$ will be exceeded, given an event of magnitude $M_{i}$ at distance $r_{j}$ in source $n$ with seismicity parameters $S_{n}$. The three functions $\lambda_{n}\left(M_{i} \mid S_{n}\right), P_{n}\left(r_{j} \mid M_{i} S_{n}\right)$ and $G_{n}\left(z \mid r_{j} M_{i} S_{n}\right)$ model the inherent stochastic uncertainty in the frequency of occurrence and location of earthquakes and in the attenuation of seismic waves.

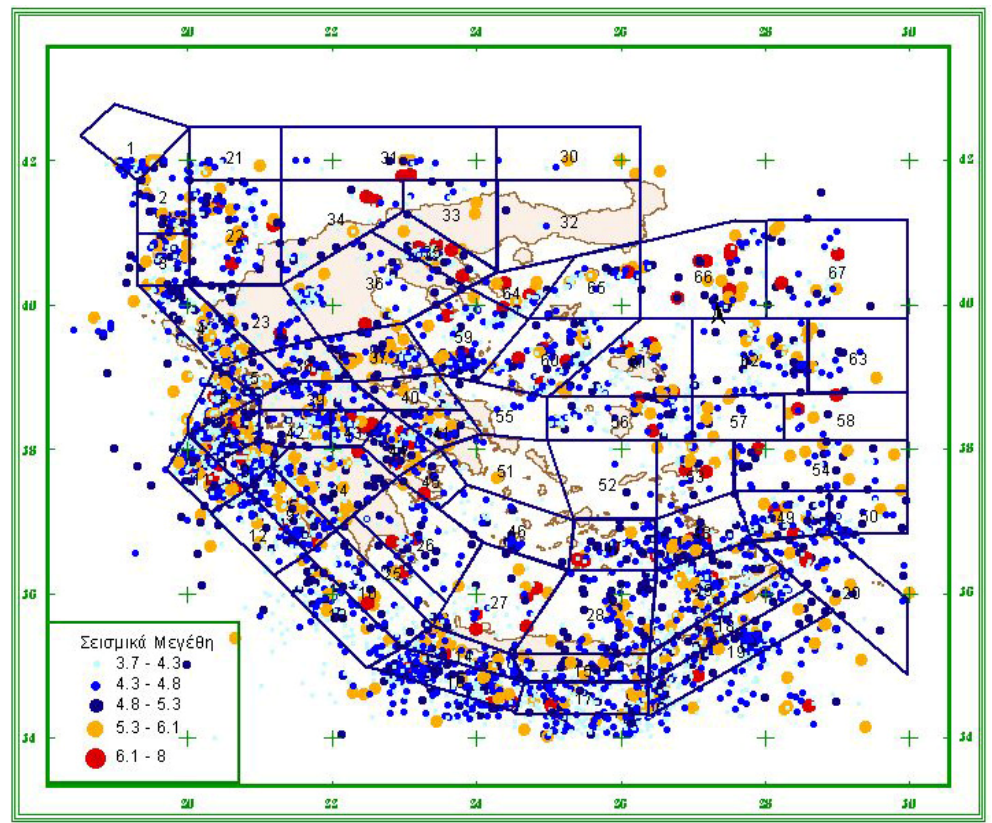

Figure 4: Historic and recent seismicity of Greece [11] and seismogenic source zones [12].

Given that the mean number of events per unit time for which $Z$ exceeds $z$ is expressed, for example, as $1 / T_{R}$, where $T_{R}$ is the return period (inverse of annual exceedance probability), then the number of events in a time period $T$ (e.g. the life time of a certain construction) for which $Z$ exceeds $z$ is given by $T / T_{R}$ and the probability for $Z$ exceeding $z$ during that life time $T$ is given by:

$$
\mathrm{P}(Z>z)=1-\mathrm{e}^{-T / T_{R}}
$$


For a lifetime $T$ of 50 years and a return period $T_{R}$ of 475 years (annual probability of exceedance $0.211 \times 10^{-2}$ ), the probability for $\mathrm{Z}$ exceeding $\mathrm{z}$ becomes 0.1 , corresponding to $90 \%$ probability that this size ground motion is not exceeded in 50 years. With several seismic sources, described through particular model parameters, the mean number of events per unit time in which the ground motion level is exceeded can be expressed specifically, involving functions that model the inherent stochastic uncertainty in the frequency and location of earthquakes and in the attenuation of the seismic waves.

Besides this natural uncertainty, there is also an element of uncertainty associated with the variability of model parameters. This source of uncertainty is accounted for by regarding these parameters as random variables, whose discrete values are assigned weights reflecting their likelihood.

The algorithm outputs directly the Probabilistic Seismic Hazard Analysis (PSHA) in contour maps of Arias Intensity (in $\mathrm{m} / \mathrm{s}$ ) that has a $90 \%$ probability of not being exceeded in various returning periods for the seismic basement of the territory of Greece. The hazard calculations are been performed using the SEISRISKIII algorithm by Bender and Perkins [13].

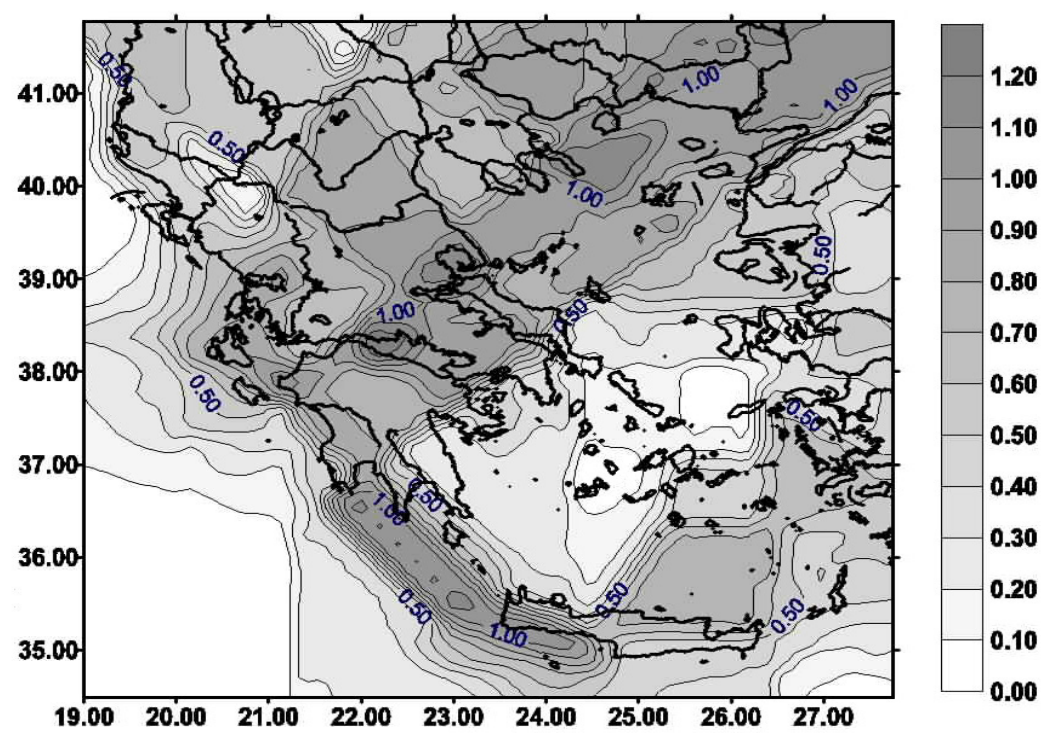

Figure 5: $\quad I_{a}$ hazard map in units of $\mathrm{m} / \mathrm{s}$ for the territory of Greece with $90 \%$ probability of not being exceeded during a period of 50 years.

The above mentioned seismic source model which is proposed for the territory of Greece by Papaioannou and Papazachos [12] and the attenuation model of Arias Intensity $I_{a}$ proposed by the authors using rock site conditions were used to create seismic hazard maps of $I_{a}$, for a period of 50 and 100 years with $90 \%$ probability of non-exceedance. Figs. 5 and 6 depict the obtained results. 


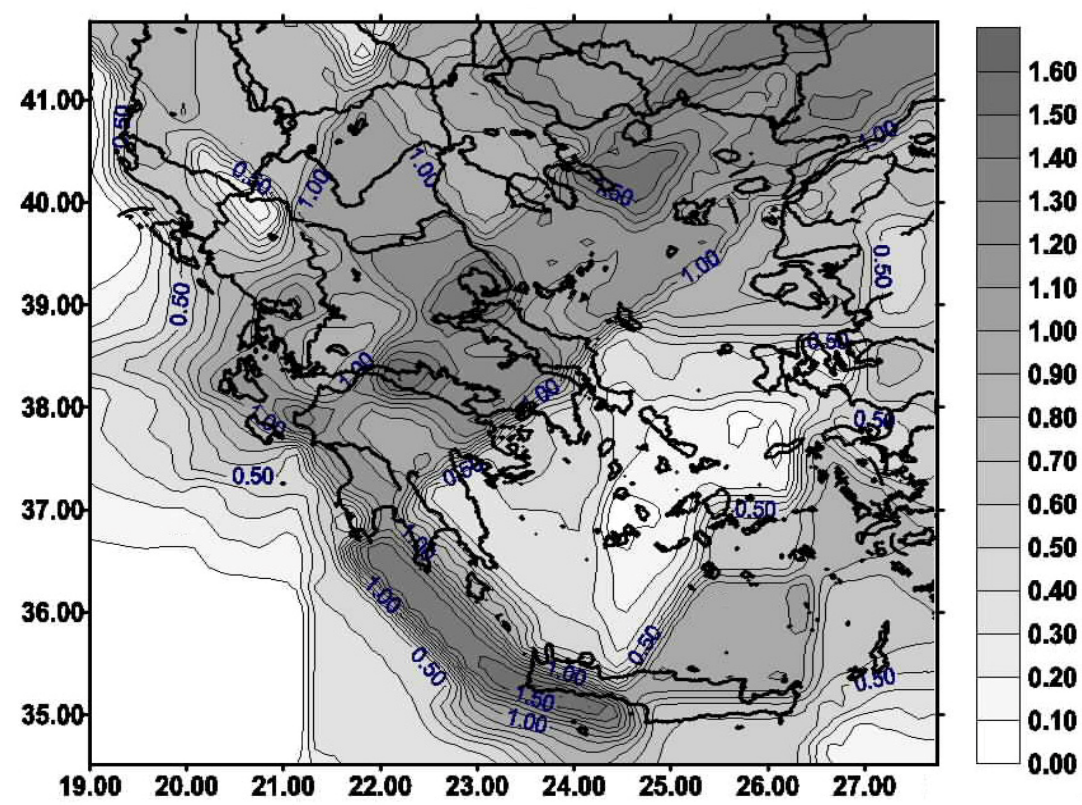

Figure 6: $\quad I_{a}$ hazard map in units of $\mathrm{m} / \mathrm{s}$ for the territory of Greece with $90 \%$ probability of not being exceeded during a period of 100 years (long-term prediction).

The presented $I_{a}$ seismic hazard maps, figs. 5 and 6 , can be used additionally as a basis for a seismic hazard landslide mapping in the territory of Greece. Arias Intensity is correlated with earthquake induced landslides and soil liquefaction, too. Keefer and Wilson [2] defined thresholds of Arias Intensity beyond which the occurrence of certain types of seismically triggered slope instability becomes possible: Type I: falls, disrupted slides $-I_{a}$ threshold of $0.11 \mathrm{~m} / \mathrm{s}$; Type II: slumps, block slides and earth flows $-I_{a}$ threshold of $0.32 \mathrm{~m} / \mathrm{s}$; Type III: lateral spreads and flows $-I_{a}$ threshold of $0.54 \mathrm{~m} / \mathrm{s}$.

\section{Conclusions}

Empirical attenuation relationships of Arias Intensity for three different site conditions have been proposed. This study is region-specific, as records from events that have occurred in Greece only have been used in the analysis. The regressed values of Arias Intensity for soft and stiff soil are higher than those for rock sites. Using Arias Intensity in seismic hazard analysis could provide improved earthquake scenarios in terms of ground motions that are most representative of the structural damaging. The compiled maps also show that there are regions within continental Greece (where high topographic relief are encountered) with significant slope instability potential. 


\section{Acknowledgements}

This work has been partially financed by EC contracts SHIELDS/NNE5/1999/381 and AEGIS IST/2000/26450. The last two authors are grateful to the Greek State Scholarships foundation (I.K.Y.) for financial support.

\section{References}

[1] Arias, A., A measure of earthquake intensity. Seismic Design for Nuclear Power Plant, ed. R.J. Hansen, MIT Press: Cambridge, MA, pp. 438-483, 1970.

[2] Keefer, D.K. \& Wilson, R.C., Predicting earthquake induced landslides with emphasis on arid or semi-arid environments. Landslides in a Semi-Arid Environment, eds. P.M. Sadler \& D.M. Morton, Inland Geological Society, 2, pp. 118-149, 1989.

[3] Kayen, R.E. \& Mitchell, J.K., Assessment of liquefaction potential during earthquakes by Arias Intensity. Journal of Geotechnical and Geoenvironmental Engineering, ASCE, 123, pp. 1162-1174, 1997.

[4] Paciello, A., Rinaldis, D. \& Romeo, R., Incorporating ground motion parameters related to earthquake damage into seismic hazard analysis. Proc. of the $6^{\text {th }}$ Int. Conf. on Seismic Zonation: Managing Earthquake Risk in the 21st Century, Earthquake Eng. Res. Inst., Oakland, CA, pp. 321-326, 2000.

[5] Travasarou, T., Bray, J.B. \& Abrahamson, A., Empirical attenuation relationship for Arias Intensity. Earthquake Engineering and Structural Dynamics, 32, pp. 1133-1155, 2003.

[6] Ambraseys, N., Smit, P., Sigbjornsson, R., Suhadolc, P. \& Margaris, B., Internet-Site for European strong-motion data, European Commission, Research-Directorate General, Environment and Climate Programme, 2002.

[7] Pinheiro, J.C. \& Bates, D.M., Mixed-Effects Models in S and S-Plus, Springer: New York, 2000.

[8] S-plus. S-Plus Software, Mathsoft, Inc, 2000.

[9] Scarlatoudis, A.A., Papazachos, B.C., Margaris, B.N., Theodulidis, N., Papaioannou, Ch., Kalogeras, I., Scordilis, E.M. \& Karakostas, V., Empirical peak ground-motion predictive relations for shallow earthquakes in Greece. Bulletin of the Seismological Society of America, 93, pp. 2591-2603, 2003.

[10] Billiris, H., Paradissis, D., Veis, G., England, P., Feathestone, W., Parsons, B., Rands, P., Rayson, M., Sellers, P., Ashkenazi, V., Davison, M., Jackson, J. \& Ambrasseys, N., Geodetic determination of tectonic deformation in Central Greece from 1900 to 1988. Nature, 350, pp. 124-129, 1991.

[11] Papazachos, B.C., Comninakis, P.E., Karakaisis, G.F., Karakostas, B.G., Papaioannou, Ch.A., Papazachos, C.B. \& Scordilis, E.M., A catalogue of earthquakes in Greece and surrounding area for the period 550BC-1999, Publ. Geoph. Lab. Univ. of Thessaloniki, pp. 1-333, 2000. 
134 Earthquake Ground Motion: Input Definition for Aseismic Design

[12] Papaioannou, Ch.A. \& Papazachos, B.C., Time-independent and timedepended seismic hazard in Greece based on seismogenic sources. Bulletin of the Seismological Society of America, 90, pp. 22-33, 2000.

[13] Bender, B.K. \& Perkins, D.M., SEISRISKIII - A computer program for seismic hazard estimation: U.S. Geological Survey Bulletin 1772, pp. 1-48, 1987. 